\title{
Las alamedas en la España Moderna. Interpretación histórica de un espacio urbano/
}

\author{
The Alamedas in Early Modern Spain. \\ Historical Interpretation of an Urban Space
}

Manuel F. Fernández Chaves

Universidad de Sevilla

El presente trabajo constituye una síntesis historiográfica sobre el origen y el significado histórico y urbanístico que representa el surgimiento y difusión de las alamedas en la España moderna. En él se realiza un exhaustivo recorrido bibliográfico sobre las alamedas más importantes, prestando especial atención a las causas de su creación y la evolución que fueron experimentando a lo largo del periodo de estudio.

Palabras Clave: Alamedas; Edad Moderna; España; Urbanismo.

This work offers an historiographical synthesis about the origin and historical and urbanistic significance represented by the creation and spreading of the alamedas in Early Modern Spain. Through an exhaustive bibliographical survey about the most important alamedas, the author pays special attention to the reasons behind their creation and the evolution that they experimented all along the studied period.

KEYWORDS: Alamedas; Early Modern; History; Spain; Urbanism. 
Sí, que no siempre se está en los templos; no siempre se ocupan los oratorios; no siempre se asiste a los negocios, por calificados que sean. Horas hay de recreación, donde el afligido espíritu descanse. Para este efecto se plantan las alamedas, se buscan las fuentes, se allanan las cuestas y se cultivan con curiosidad los jardines. ${ }^{1}$

\section{Propósito}

La preocupación por el buen ordenamiento de la ciudad en España contó desde la Edad Media con el puntual abastecimiento alimentario y en menor medida, de agua, y con una preocupación por una correcta disposición de la trama urbana que facilitase la circulación del aire, aguas y personas. La no invasión de las calles, la apropiada edificación de las casas y la eliminación de los inmuebles ruinosos y muladares, así como el desagüe de las aguas fecales y las contaminadas por actividades textiles, entre otros temas, fueron una constante en la España medieval, musulmana y cristiana. El interés por la dignificación del espacio urbano pasaba en muchas ocasiones por la apertura de espacios diáfanos que sirvieran no solo al tránsito y regulación de usos mercantiles y de encuentro político, sino también a realzar la presencia de fachadas de edificios singulares. ${ }^{2}$ Es sin duda en el siglo XV en Castilla y Aragón, un momento en el que se van impulsando tanto desde los concejos como desde la monarquía, iniciativas no siempre coordinadas que implementaban una serie de ideas relativas al ornato y la «honra» de la ciudad ${ }^{3}$ que prefiguran los conceptos de ordenación y policía urbana que tendrán su gran auge en la centuria ilustrada, no solo en España sino en toda Europa. ${ }^{4}$ Ya los Reyes Católicos daban una pragmática en 1500 que procuraba que los corregidores velasen por el buen orden de la ciudad por encima de los intereses de los concejos, ${ }^{5}$ aunque no puede olvidarse que estos también regularían estas necesidades urbanísticas contando con el oficio de los alarifes y sus propias disposiciones. ${ }^{6}$ Estas ideas adqui-

1 Cervantes Saavedra, «Prólogo al lector», 2001 (1613), 18

2 Anguita Cantero, 1997, 27-98.

3 Bonachía Hernando, 1996. Sobre la honra urbana y el uso del agua, Val Valdivieso, 2003.

4 Muestra de esta continuidad está en el estudio comparado y seriado de ordenanzas municipales, y que tienen en Juan de Torija y Teodoro Ardemans los primeros grandes compiladores para Castilla desde la palestra cortesana, antecediendo Torija las aportaciones y sistematizaciones borbónicas. Un tratamiento general del tema, Sabaté Bel, 2010. Para Ardemans, Blasco Esquivias, 1992.

5 Anguita Cantero, 1997, 61-64.

6 Sobre los alarifes en la Edad Media española, Cómez Ramos, 2006. 
rieron un gran impulso al calor de la expansión demográfica, económica y política de la Monarquía Hispánica en el siglo XVI, transformándose la vocación de muchos espacios urbanos y la morfología parcial de grandes y pequeños núcleos de población, ${ }^{7}$ y la preocupación por el aspecto y organización de la ciudad tuvo un gran eco en el corpus de ordenanzas locales que se dieron a nivel peninsular y especialmente en la Junta de Ornato y Policía de Madrid creada en el siglo XVI y en las distintas medidas y ordenanzas destinadas a regular ornato y policía en la corte. ${ }^{8}$ Este impulso de transformación urbanística continuará en el siglo XVII, para acelerarse de nuevo en la centuria siguiente, en la que el papel de orientación y estímulo director de la Monarquía será muy importante. Entre los elementos constitutivos de la nueva faz de muchas ciudades, se contaban los intentos por generar un urbanismo estéticamente armónico; la apertura de espacios placenteros; la creación, renovación y ampliación de sistemas de abastecimiento hidráulico, con la consiguiente construcción de fuentes; el impulso de la limpieza urbana; el ensanche y alineación de calles y el surgimiento de los primeros jardines públicos en forma de paseos arbolados, llamados alamedas. En este trabajo vamos a trazar una panorámica general de la creación y crecimiento de las alamedas y paseos en la España de los siglos modernos, para comprender su importancia y evolución en las ciudades peninsulares. No pretendemos ofrecer un catálogo exhaustivo de todas las alamedas creadas en la España moderna sino entender su origen y funcionalidad, así como conocer sus principales características y evolución.

La proliferación de alamedas en el siglo XVIII ha hecho pensar en ocasiones que estos equipamientos eran propios de dicha centuria, y en parte ello es comprensible puesto que al considerar las láminas de Patte y el desarrollo urbanístico de París en el siglo XVII Gravagnuolo indica:

Más aún que los objetos de ornato - fuentes, obeliscos, estatuas y otras piezas decorativas...- resaltan los largos boulevards arbolados y las amplias places royales, dos elementos que tienen una larga génesis en el proceso de construcción histórica de las ciudades europeas, pero que asumen una inusitada validez y una particular fisonomía en la transformación de París... la red de recorridos arbolados, bien integrada en el

7 Castillo de Bobadilla trata in extenso la importancia del ornato público manifestado en la arquitectura y traza urbana, en el acometimiento de todo tipo de obras públicas, así como en la necesidad de contar con fuentes de agua y de mantener la limpieza de las calles, «pues, como queda dicho, tanto hermosean los Pueblos, y las obras y cosas magníficas, más se encomiendan por el ornato público que por la utilidad de ellas». Castillo de Bobadilla, 1775, t. 2, 86.

8 Blasco Esquivias, 1992. 
sistema de los parques... se convierte no solo en el nuevo cauce de las relaciones entre la capital y el hinterland sino también, en muchos aspectos, en un símbolo de la nueva ciudad «solar». ${ }^{9}$

El urbanismo barroco potenció y utilizó los ejes viarios arbolados para organizar las ciudades y relacionarlas con su entorno inmediato, idea que volveremos a ver al final de este trabajo, al tiempo que estos ejes viarios eran también el alma de la organización espacial de ciudades palaciegas como Versalles o Karlsruhe, Aranjuez, Bonn, etc. ${ }^{10}$ Pero el origen de estos espacios, donde el jardín público y el paseo se disponen al abrigo de murallas o surgen sobre un camino cercano a la ciudad, puede remontarse al menos al siglo XVI, y si bien es cierto que no habían adquirido todavía el valor de elemento de primer rango en el orden urbanístico que estos paseos-eje adquirirán en el Barroco, ya transformaban el urbanismo y el uso social del mismo. Recientemente y siguiendo a Henry W. Lawrence, ${ }^{11}$ Laurent Paya ha señalado la influencia de la jardinería italiana y flamenca en la formación de estos espacios en el siglo XVI, tanto extramuros de ciudades como Lucca (paseos arbolados que flanquean la muralla desde 1546), como sobre todo en la alameda de Lange Vijverberg en La Haya de 1553. Paya recoge las aportaciones de Albardonedo Freire y Lopezosa Aparicio entre otros, y señala la conexión que existe entre el conocimiento de Felipe II de las ciudades y jardines flamencos y el impulso de alamedas tanto en el Prado como en Sevilla y otras ciudades. Dicho impulso se dio precisamente en las décadas de los años 70 y 80 del siglo XVI, algo que ya había apuntado la historiografía pero que el autor refuerza al vincular la creación de estos espacios con la que tiene lugar en el continente americano, en un proceso de construcción y revocación constante. ${ }^{12}$

\section{Una definición de las alamedas}

Las alamedas son, en esencia, un jardín público en el que los árboles juegan un papel esencial al ordenar el espacio para que sea recorrido longitudinalmente, con lo que el movimiento de sus visitantes es estimulado

\footnotetext{
9 Gravagnuolo, 1998, 20.

10 Braunfels, 1983; Sica, 1982.

11 Lawrence, 2008.

12 Paya, 2014.
} 
al tiempo que delimitado en el espacio que marca el eje del paseo. ${ }^{13}$ Nacen como tales en el siglo XVI, si bien existen precedentes medievales y por supuesto en el mundo clásico, pues su base es un camino, su función es ser recorridas y cuentan siempre con árboles. El riego es vital para su mantenimiento, y generalmente esta necesidad se convierte en virtud al contar con fuentes que además de cumplir con una función de refresco y embellecimiento, refuerzan el carácter axial de este espacio y lo dotan de hitos emblemáticos cuando están decoradas con programas iconográficos, que generalmente aluden a la monarquía, a través de alusiones paganas o a héroes de la Antigüedad, así como al poder del corregidor, intendente o munícipes que las impulsaron. El dinamismo de las alamedas puede ser detenido en torno a estas fuentes que son espacio natural de sociabilidad, y también en asientos con los que muchas de ellas contaban, quedando el transeúnte convertido en observador de los que pasan.

Junto a estas alamedas dotadas de fuentes, bancos, varias calles y un programa iconográfico más o menos ambicioso, tenemos los paseos arbolados, que en esencia constituyen una versión simplificada de las alamedas y que en muchos casos constituirían el núcleo de una futura alameda. Están constituidos por el camino flanqueado por árboles, y estando próximos a las poblaciones su creación y mantenimiento eran más sencillos que el de una alameda; aunque habían existido casi desde siempre, su proliferación fue en aumento a partir del siglo XVI, formando un continuum de verde en torno a las poblaciones.

El agua es un elemento esencial en las alamedas, primero porque la cubierta vegetal (fundamentalmente árboles) necesita de riego, y segundo porque la construcción de fuentes servía no solo para marcar el diseño ortogonal del espacio, sino también para abastecimiento de las gentes que frecuentaban la zona. El agua corriente presente a través de fuentes y pilares constituía por tanto un nodo de urbanización fundamental, como lo prueba por ejemplo la construcción de estos surtidores en las plazas del Realejo y del Campo del Príncipe para dotar de una infraestructura básica estos espacios polivalentes en Granada. ${ }^{14}$

La creación de alamedas responde además a un esfuerzo urbanístico, interrumpido en algunas ocasiones, pero que en la larga duración se impuso en la mayoría de los casos, por ampliar las dotaciones de agua corriente

13 Sobre la definición y función de las alamedas, tomando como caso paradigmático la de Hércules de Sevilla, véase, Albardonedo Freire, 1998 (135-140) y 2002 (191-208).

14 López Guzmán, 1987, 87-89. 
en las ciudades y ensanchar los espacios urbanos, dotándolos de arbolado en el caso de estos paseos. Por ello no puede separarse su creación y fomento de la multiplicación de los puntos de abastecimiento de agua corriente, públicos y privados, que se produce a lo largo de toda la Edad Moderna. ${ }^{15}$ Es ya en el Setecientos cuando la lucha por el agua potable y contra el agua invasora de las inundaciones y el agua estancada, a través de las mejoras en el drenaje de las ciudades, persigue una reforma hidráulica en profundidad, que responde al «saneamiento habitacional» y al «saneamiento ambiental» que multiplica los «espacios verdes» y que se impone para hacer frente al aumento de la población. ${ }^{16}$ Podemos decir por tanto que la creación y difusión de las alamedas corrió paralela a la ampliación propia de la Edad Moderna de la explotación de los recursos de abastecimiento de agua potable y saneamiento de espacios de aguas muertas como lagunas, etc., en todas las poblaciones donde se desarrolló con mayor fuerza la sensibilidad para con la creación y uso de estos espacios ajardinados de carácter público, e incluso se construyeron nuevos viajes de agua «ex profeso» para dotar y equipar estos lugares, siendo un caso claro el de la alameda de Hércules de Sevilla, ciudad que vio así aumentado su nivel de abastecimiento de agua potable en el siglo XVI y de nuevo en el siglo XVIII, al tiempo que pudo ampliar el número de fuentes públicas en una zona de la ciudad tradicionalmente desprovista de ellas. ${ }^{17}$ No obstante, la difusión del agua pública no dejó de producirse durante estos siglos, aunque el concepto de ciudad plenamente abastecida no se impuso, y tampoco la idea de que dicho abastecimiento y la expulsión de aguas residuales debían ser consideradas como un binomio inseparable.

Asimismo, la modernidad de estos espacios radica en su capacidad para contar no solo con el paseante a pie o a caballo, sino también con el carruaje, que se va a convertir en el símbolo de estatus social más furiosamente de moda en los siglos modernos, que permitía revolucionariamente ver sin ser visto en movimiento y con un costoso carruaje a su disposición. ${ }^{18}$ Las alamedas suelen situarse extramuros (aunque no siempre), ${ }^{19}$ cerca de puertas de la ciudad o caminos de acceso o perimetrales (cuando no sobre

15 Fernández Chaves, 2012. El caso de Granada, entre otros muchos que podrían citarse, en Olmedo Sánchez, 2002, 157-164. Valladolid en Merino Beato, 1989, t. 1, 130-149.

16 Reguera Rodríguez, 1993, 122, 154 y 165-201.

17 Albardonedo Freire, 1998; Fernández Chaves, 2007a y 2011.

18 López Álvarez, 2007; Sanz de la Higuera, 2002-2003.

19 Como es el caso de la alameda de Sevilla, una de las primeras en su género y construida en el interior de la ciudad. 
ellos), ${ }^{20}$ y su uso las dota de una vocación propia, en la que el espacio abierto de naturaleza ajardinada se llena con la presencia humana pululante y constante, dejando los edificios que pueden surgir a su alrededor marcados por el vacío esencial que las constituye. ${ }^{21}$ En este sentido, las alamedas cumplen también una función no escrita que permite conquistar un espacio poco urbanizado por distintas causas para la edificación y para la expansión de las zonas habitadas.

Esa modernidad también se revela en la creación de un jardín público que se asume en el tejido urbano. Ello fue consustancial a las primeras alamedas, como la de Hércules en Sevilla, que permitieron la integración de la naturaleza en la urbe, de forma que:

En el proyecto de la alameda están recogidos los presupuestos teóricos de la tratadística de jardinería. Así el agua y el verde se organizan en formas dominadas por el pensamiento del hombre; ejemplo claro de la influencia italiana lo presenta el organicismo de los ejes e hiladas de árboles; la simbiosis de naturaleza y el arte o el deseo de aunar y proyectar sobre dos elementos de gran valor en el entorno humanista: el paisaje y el material arqueológico. ${ }^{22}$

Y este jardín permanente en cuya creación jugó un predominio claro el jardín-emblema humanista tenía su contrapunto en los jardines que de manera efímera se creaban en claustros de conventos y plazas con motivo de las fiestas religiosas y profanas durante toda la Edad Moderna, donde se reproducían jardines que servían de escenarios como

la reinvención, en el lenguaje espectacular de la fiesta, de las tres grandes tradiciones del jardín desde la Antigüedad: el locus amoenus de la tradición clásica, el modelo bíblico del paraíso original y la tradición ascética medieval. De las tres tradiciones, la del jardín palatino parece ser la más viva en la mentalidad de los artífices del fasto barroco, sobre todo tras los ricos hallazgos de la tradición manierista. Es el modelo que aporta el concepto de perspectiva al diseño del espacio y la experiencia de los ingenios hidráulicos y juegos de ilusión. ${ }^{23}$

20 Ello es una constante lógica. En el siglo XVIII se siguen construyendo alamedas en caminos como en Álava o Burgos, el camino de Carabanchel, dándose órdenes para que los pueblos situados en la carretera entre Madrid y el arroyo de Portugal compusiesen «las entradas y salidas de ellos, así como las calles principales y de paso preciso para los caminantes» en 1785, incluyéndose el plantío de árboles, Sambricio, 1991, t. 1, 218-220.

21 Ya defendimos la ausencia en las alamedas de una vocación urbanística definida, en relación a la falta de edificios civiles o religiosos importantes en su entorno. Fue esta una de las principales características de la alameda de Hércules en Sevilla: su vacío es su esencia. Fernández Chaves, 2007a. La idea de la alameda como espacio desacralizado también en Peñafiel Ramón 2006, 52; García Gómez, 1995.

22 Albardonedo Freire, 1998, 155.

23 García Bernal, 2006, 457; también Sica, 1977, 98-99. 
Además de lo aquí expuesto no debe olvidarse que las alamedas suponen la conquista de un espacio desordenado, con muladares, barrizales, cultivos, etc., que constituyen además una zona de difícil paso, como fueron la laguna de la alameda de Hércules, el espacio junto al río de Córdoba, etc., donde la naturaleza recreada sirve para el solaz de los habitantes de la ciudad al tiempo que se convierte en el eje de ordenación del espacio. De esta manera, la perspectiva amplia y la visión despejada desde múltiples lugares y el acceso generalizado convertían a estos espacios de sociabilidad en espacios donde practicar un «ocio honesto» precisamente por estar a la vista de todos. ${ }^{24}$ No en vano parte de los prados cercanos a cuevas y ermitas extramuros de Jaén fueron transformados en una alameda en 1577 para, entre otras finalidades, limitar la libertad de los comportamientos sociales que tenían lugar en aquellas extensiones pues «era tanta la afluencia del pueblo que concurría a aquel lugar, que se hacía notar más la relajación que la devoción, más los pecados que los servicios a Dios». ${ }^{25}$ Ello significa que una alameda era también la reorganización de la actividad de descanso y refresco que se practicaba espontáneamente por los habitantes de la ciudad, que ahora son dirigidos a un espacio apropiado para el decoro, presidido por programas iconográficos acordes con la cultura imperante del momento. En definitiva, se reorganiza el espacio para redefinir los comportamientos sociales, siendo el lugar del paseo espacio para el encuentro galante $(\mathrm{y}$ no tanto), ${ }^{26}$ temido por algunos como demasiado abierto a la ruptura de las normas sociales. ${ }^{27}$ No en vano el corregidor de Salamanca proyectaba en el siglo XVIII crear un paseo en el campo de San Francisco

que pudiera servir para todas las estaciones del año y evitar, por ese medio las picardías y excesos que, con el escándalo más público, se cometían en las vecinas parbas de labradores, a donde, escalando la muralla, se retiraban las gentes a tomar el

24 Así, la «diversión» constituyó siempre uno de los motivos de fomento del Prado en Madrid, manifestado en parte en su proyección espacial y escultórica (Reese, 1989, 33), y que se transmitía al Retiro, donde Aranda había inaugurado en 1767 «más de mil sillas para que puedan sentarse las gentes, cafés con bebidas, chicle, café, etc. unas tiendas y barcos que dicen se pondrán en los estanques... siendo lindísimo y muy acompañado de gente sin capa ni mantilla... botillerías y sillas muchas en todas partes para sentarse». Reese, 1989, 33, 6. Un texto complementario en Martín Gaite, 1981, 46. Sobre estos espacios y el valor de los bailes en ellos, Molina Martín, 2013, 335-340.

25 López Cordero, 2003.

26 Sobre este ocio honesto, sus hipocresías y los límites del «cortejo» de las damas que será objeto de atención de los viajeros, véase Martín Gaite, 1981, en general, y para la exhibición en el paseo y los acontecimientos sociales a él asociados, 31-32, 46-50 y ss.

27 Como es el caso de Murcia. Peñafiel Ramón, 2006, 79-80. 
fresco, fumaban entre las mieses con peligro de incendiarlas, se ocultaban y originaban mil disparates. ${ }^{28}$

De esta manera, a la intención por crear un espacio más salubre donde la naturaleza está organizada para generar un lugar umbrío, fresco y ameno, se unirá en el siglo XVIII la preocupación por generar entornos urbanos que permitan dignificar, en el sentido social de la palabra, los espacios de encuentro y expulsar fuera de los límites urbanos los comportamientos, que siempre se dieron, menos atractivos para el poder. No se olvide que habría que añadir al hecho de que los espacios abiertos como la laguna de la Feria, donde luego se construiría la alameda de Hércules en Sevilla, fueron lugares donde se practicaba el ejercicio atlético y de caballeros, incluso después de acondicionado el lugar.

Pero además de haber sido escenario de los juegos y encuentros de la nobleza, estos espacios abiertos también dieron cobijo, sobre todo extramuros, a todo tipo de actividades y violencias, y por ello las alamedas no siempre fueron un espacio de encuentro galante, sino también de pendencias como reflejan algunos cuadros sobre la alameda de Hércules, donde por ejemplo en 1630 el asistente «había hecho quemar en la Alameda un truque, sillas y vaços de una casa de conversación». ${ }^{29}$ En las alamedas también se ventilaban pendencias, como muestran los distintos cuadros pintados sobre la de Sevilla. ${ }^{30}$ De todas formas las alamedas gozaron siempre de una imagen positiva y sobre ellas concluye Paya:

L'Alameda est donc un «lieu commun» vers lequel convergent les caractéristiques des promenades d'Espagne, même s'il existe une certaine diversification du modèle... sont créés hors les murs, dans des paysages encore agrestes ou marécageux, pour connecter des sanctuaires du pouvoir monarchique catholique à la cité... elles définissent un espace social et architectural de plein air propice aux rituels courtois aristocratiques. ${ }^{31}$

\section{Las alamedas en el siglo XVI}

Las alamedas tal y como han sido descritas anteriormente no comienzan a surgir hasta el tercer cuarto del Quinientos. Ya existen por separado todos los elementos que las constituyen, como jardines de árboles, fuen-

28 Sambricio, 1991, t. 1, 228

29 Morales Padrón, 1981, 26.

30 Podemos tomar como ejemplo el que se exhibe en la Fundación Focus Abengoa de la capital hispalense, de ca. 1647, cedido por The Hispanic Society of America.

31 Paya, 2014, 13. 
tes..., pero no han desarrollado plenamente el carácter de alameda como conquista urbana de la naturaleza integrada en un jardín público. Uno de los ejemplos más tempranos es el del plantío de árboles y allanamiento del camino paralelo al río Eresma en Segovia en 1560, cuyo cauce vertebraba un paseo que ya en 1573 había adquirido la consideración del cabildo como «lugar de recreo y embellecimiento de la ciudad». ${ }^{32}$ Lo temprano de su formación y consideración como paseo público, creado y cuidado permanentemente por el cabildo segoviano lo configuran como uno de los más preclaros y tempranos ejemplos de una alameda tal y como la entendemos. ${ }^{33}$ Otro tanto puede decirse del paseo arbolado junto al Guadalquivir en Córdoba, que desde 1553 va creándose sobre la ribera hasta la puerta del puente romano, para ser ampliado con el impulso del corregidor (entre 1567 y 1571) ${ }^{34}$ Francisco Zapata de Cisneros, quien como veremos también fue el gran patrocinador de la alameda de Hércules en Sevilla. Antes de su marcha a Sevilla en 1571, realizó un plantío de álamos en una zona del paseo a partir del arco de la Albolafia, dándole el pleno carácter de alameda, y a partir de ese momento se sucedieron las obras de ampliación, allanamiento del terreno y empedrado «para que se pueda pasar bien por allí bien a pie y a caballo», acondicionándose el acceso al río y dotándose el espacio una fuente, consolidándose así una alameda propia del nuevo urbanismo renacentista. ${ }^{35}$ En 1587 el cabildo justificaba la continuidad de las obras recordando que:

conviene que se haga una salida en esta ciudad por donde los caballeros y ciudadanos se salgan a tomar el fresco en verano y el sol en invierno y a ejercitarse la gente de caballo y que en ninguna parte de esta ciudad hay lugar más acomodado que la carrera de la Fuente de las Arcas como se ha visto por experiencia este año en lo poco que allí se ha hecho [...] y porque se ha acordado por la ciudad que los barcos no anden en el río se determinó asimismo para que la gente se pueda bañar y pasara a los nadaderos de la isla y alameda por ser partes ocultas y decentes y donde ocurre siempre toda la mayor parte de la ciudad....

32 Sanz Sanjosé, 2004. Paya retarda la creación de esta alameda a la presencia de Felipe II en la ciudad por su boda con Ana de Austria en 1573, pero como aquí se indica la creación de este espacio parte del concejo y es anterior, si bien es claro que la presencia del rey tuvo que influir en su conformación y consolidación. Asimismo, tampoco considera en este proceso la ciudad de Córdoba, crucial como veremos enseguida, por la presencia del corregidor Zapata. Paya, 2014, 7.

33 Ruiz Hernando, 1982, t. 1, 131-132.

34 García Cano, 2003, t. 1, 459-466; Albardonedo Freire, 1998, 138-139.

35 Puchol Caballero, 1992, 148-151; García Cano, 2003, t. 1, 482.

36 Cit. por Puchol Caballero, 1992, 149 y 151. 
Este texto es uno de los ejemplos más claros sobre el papel que juegan las alamedas como espacio de sociabilidad por excelencia, donde el ejercicio, el encuentro social y el goce del aire limpio y el agua en los meses más calurosos juegan un papel esencial, y como decían los regidores la obra era «muy buena y muy necesaria para ornato de esta ciudad [y] ejercicio de los caballeros de ella». ${ }^{37} \mathrm{Y}$ de nuevo como en Segovia el fundamento de la alameda se organiza entre las murallas y un río, articulándose el espacio sobre una vía perimetral que enlaza con caminos de salida de la ciudad y donde los árboles juegan el triple papel de límite, estructuración de la perspectiva y provisión de sombra. Las alamedas de Segovia y Córdoba tienen pues muchos puntos en común, y uno de los más importantes lo constituye la iniciativa concejil para crear y dotar estos espacios. El corregidor Zapata fue uno de los más preclaros transformadores del urbanismo cordobés, y su labor continuaría en la ciudad de Sevilla, con el impulso de numerosas reformas entre las que también se cuenta la creación de la alameda de Hércules (1574), obra magna que supuso la colonización de un gran espacio intramuros ocupado por la «laguna de la Feria» que se rellenó, terraplenó y empedró, conservándose su disposición para seguir sirviendo como desagüe de la parte más alta de la ciudad que la rodeaba, a través del husillo real que daba al río Guadalquivir, al tiempo que se diseñaba una alameda considerada por la ciudad como una ocasión para aumentar el «ornato desta çibdad» para lo que,

convendrá que la çibdad provea cavalleros comisarios para que vean y provean serca de lo que se ha de hazer en la laguna desta cibdad para las fuentes y paseos que alli sera bien que se haga porque sera cosa muy señalada y de un gran ornato para esta çibdad lo que alli se podra hazer con poca costa asi como de fuentes y plantas y alnuela [sic] como de todo lo que fuere neçesario para el dicho ornato y acequias y madres por donde aya de yr el agua. ${ }^{38}$

La alameda de Hércules era todo un jardín manierista en el que el programa iconográfico humanista ${ }^{39}$ que constituía la erección de las columnas de un viejo templo romano coronadas por sendas estatuas de Hércules y Julio César venía a asumir la vinculación de la monarquía con la ciudad, al tiempo que se recuperaba una zona degradada y se construía el segundo sistema de abastecimiento de agua más importante después de los Caños de

37 Ibidem, 237.

38 Albardonedo Freire, 1998, 144.

39 Solís de los Santos, 2012; Lleó Cañal, 2012; Albardonedo Freire, 2002, 204-208. 
Carmona. ${ }^{40}$ Su creación dio lugar a la de otras alamedas, incluso en América ${ }^{41}$ y en lugares más cercanos como Écija, donde en 1578 se construyó una alameda también a lo largo del río Genil, retirando un muladar que existía junto al puente, en una decisión que tenía una clara influencia de la alameda de Sevilla. Ello se hizo porque el puente y la ciudad recibían «tanto perjuicio»,

por lo mal que paresce a los caminantes e personas que vienen de fuera a ella (la ciudad) e que ansimismo se le hiciese un pretil para reparo de las avenidas del río... se ve la necesidad que hay de que un lugar tan principal como éste, de que los caballeros e gente prinçipal del tengan a donde poder salirse a pasear, como lo tienen en otros lugares de estos reinos que son tan grandes como el... hagan fazer.. una alameda hasta las huertas, de manera que hagan calles y una azacaya para regar la dicha alameda, e se eche agua de dos fuentes... e... se hagan en ella dos fuentes que han de ser llanas, con dos taças... de piedra. ${ }^{42}$

Es muy posible que el corregidor Zapata hubiese actuado con la aquiescencia de Felipe II, quien precisamente había visitado Córdoba y Sevilla en 1570, con ocasión de la guerra de las Alpujarras y de las cortes celebradas en Córdoba, y aquí entra en juego la promoción de estos espacios por parte de la monarquía. Albardonedo Freire ha señalado el muy posible interés directo y fomento de Felipe II por la urbanización y ajardinamiento de estos espacios, ${ }^{43}$ y es muy interesante considerar además que la creación de la alameda segoviana también tuvo que ser contemplada por el Rey Prudente, quien en 1570 estaba en aquella ciudad donde se realizó el recibimiento de Ana de Austria y se ratificó su casamiento. El año de 1570 se antoja por tanto como crucial para la formación de las alamedas, habida cuenta de que las de Segovia, Córdoba, Sevilla y también Écija, ${ }^{44}$ están vinculadas por la persona del rey, quien en aquel año tenía en mente la remodelación del paseo del Prado, también para recibir a Ana de Austria, con lo que se daría lugar a los trabajos que lanzarían definitivamente este espacio como uno de los más influyentes en materia de jardines públicos y que serviría de ejemplo e impulso para la difusión del modelo.

\footnotetext{
40 Albardonedo Freire, 2002, 191-208.

41 Durán Montero, 1985.

42 Aguilar Diosdado y García León, 1988, 37-38.

43 Albardonedo Freire, 2002, 193-199; Lleó Cañal, 2012.

44 Además de la iniciativa municipal también sabemos que Felipe II estuvo en la ciudad y visitó el monasterio del Valle en 1570. Cfr. Aguilar Diosdado y García León, 1988.
} 


\section{Un modelo para toda la Edad Moderna: el paseo del Prado}

El paseo del Prado surge sobre un camino perimetral de Madrid y cerca de una corriente de agua, en la que ya existían previamente conjuntos arbóreos, conocidos como el Prado Viejo, por el Prado de San Jerónimo, convento fuertemente ligado a la monarquía. Su condición de principal camino de entrada a la villa supuso que en 1570 fuera embellecido con arquitecturas efímeras y arbolado con motivo de la entrada de Ana de Austria. Las dos avenidas de álamos y las fuentes que quedaron de manera permanente en la zona fueron la parte más visible de unas obras que fueron sucediéndose en el tiempo sobre este espacio, de manera que casi de manera ininterrumpida se fueron sucediendo los allanamientos del terreno, ensanche de las avenidas de álamos, multiplicación de fuentes y programas iconográficos de las mismas, así como una ampliación decidida del paseo que fue subiendo hacia el norte por la zona de Recoletos y la fuente Castellana, y hacia el sur hacia el prado y el convento de Atocha. Bajo el reinado de Felipe III se buscaron nuevas fuentes de agua y se produjo un primer ensanche, extendiéndose hacia el norte y el sur el arbolado. Las obras conocieron fuertes impulsos conforme el espacio se iba dignificando por la presencia regia, no solo por la construcción del palacio del Buen Retiro en 1634, sino también por ser uno de los escenarios del poder regio más importantes de la urbe, tanto por los acontecimientos excepcionales como las entradas reales de Margarita de Austria (1599) o Isabel de Borbón (1615) entre otras, como por ser una zona muy frecuentada por las personas reales en la que los criterios de simetría, proporción y belleza arquitectónica fueron condicionando la arquitectura y usos de los edificios que colindaban con el paseo, que no dejó de crecer y hacerse más complejo en el uso de los elementos vegetales y acuáticos, presentes en él. Se trató además de ir rectificando los regatos y arroyos como el de la Castellana o del Prado que otrora fueran el eje del mismo, para ir soterrándolos y eliminar así el peligro de avenidas y la presencia de puentes en el paseo,${ }^{45}$ hasta llegar las reformas del siglo XVIII en las que estos arroyos quedaron completamente soterrados y las aguas sucias de la ciudad también tributaron su caudal al paseo de manera subterránea, creándose un salón con dos exedras arboladas en sus extremos norte y sur, presididas por fuentes, en un proyecto desarrollado por Antonio Hermosilla y rematado por Ventura

45 Lopezosa Aparicio, 2005, 36-171. 
Rodríguez. ${ }^{46}$ Esta transformación de 1767 ha sido relacionada por Reese, y lo mantiene en lo general Lopezosa Aparicio, con la una posible relación la obra de renovación de la alameda de Hércules de Sevilla llevada a cabo en 1764, cuando se cerró su extremo norte con dos nuevas columnas, y con la Piazza Navona entre otros esquemas urbanos,${ }^{47}$ pero supera a la alameda de Hércules en la una decidida voluntad en el proyecto para soterrar las aguas negras y blancas y mejorar las condiciones del paseo. ${ }^{48}$

Por todo ello el Prado de Madrid reúne una serie de elementos clave que forman el mejor resumen de lo que es una alameda en la Edad Moderna española, a saber: creación en el siglo XVI; construcción sobre un camino previo o espacio de transición entre la ciudad y el campo y por ello ubicación generalmente extramuros; recuperación de un espacio donde las aguas corrientes en forma de arroyo o río y las aguas sucias que tradicionalmente desembocan en él tienen un protagonismo importante; allanamiento y empedrado del espacio; ordenación del mismo con el uso de la perspectiva con álamos (estilizando la visión del paseo); recurso al agua corriente canalizada para el riego y abasto de fuentes que organizan la perspectiva del paseo, sirviendo como hitos en el mismo y como soporte de programas iconográficos específicos asociados a la vocación lúdica y estética del lugar. Por último y no menos importante, la alameda del Prado constituye una solución urbanística en la que juega un papel importante su carácter de transición entre las avenidas de los jardines palaciegos y este espacio urbano cuya función esencial es la de ser ocupado, por lo que el fomento de la monarquía de estos lugares no debe pasar desapercibido. Se produce aquí un fenómeno de transformación:

En la segunda mitad del siglo XVI... inicio de un trasvase de las experiencias relacionadas con la proyección de la ciudad, y así el patrimonio proyectual, técnico-histórico y, en parte, también simbólico acumulado en las numerosas obras de jardinería de la primera mitad de siglo comenzará a fundirse gradualmente en la renovación de la instrumentación de intervención sobre las ciudades. ${ }^{49}$

46 Ibidem, 205-259.

47 Reese, 1989, 9; Lopezosa Aparicio, 2005, 205-259. Sobre la renovación de la alameda de Hércules, Fernández Chaves, 2007a; Ollero Lobato, 2004, 252-253; Pleguezuelo Hernández, 2007. Espacios similares no pasaron de proyecto, como la alameda pensada para Cartagena por el ingeniero Féringan y Cortés. Martínez Ripoll, 1977, 320-321. Y a la inversa, la influencia del Prado en otras alamedas. García Gómez, 1993.

48 Reese, 1989, 14. Sobre el sistema de desagüe de la alameda de Hércules y el general de la ciudad, Fernández Chaves, 2007a, 2007b y 2011.

49 Guidoni, Marino, 1985, 95. 
Su condición de modelo ya fue anunciada por Chueca Goitia hace años cuando lo consideró como un patrón urbanístico «nacional» que se difundiría con éxito general..$^{50}$

\section{La evolución del siglo XVII y el significado de las alamedas en los equipamientos urbanos}

Por todo lo hasta aquí expuesto las alamedas fueron adquiriendo una importancia creciente en la evolución urbanística de la España moderna, convirtiéndose en auténticos «caminos de sociabilidad» que en ocasiones se bastaban a sí mismos y en otras conducían a otros espacios emblemáticos de la ciudad (plazas, palacios, etc.), dotando de carácter propio a las actuaciones urbanísticas de la modernidad en España. Un clarísimo ejemplo de ello lo constituyen las alamedas construidas en Valladolid sobre caminos que discurrían paralelos o cerca del río y que conocieron un gran impulso con la presencia de la Corte en la ciudad. ${ }^{51}$

El caso paradigmático de Valladolid nos permite comprender estos espacios en toda su dimensión, pues si bien el impulso regio de ornato y acondicionamiento fomenta la creación de estas alamedas en la ciudad, también es cierto que el propio concejo disponía de estos espacios para sus habitantes, como es el caso del prado de la Magdalena y el paseo del Espolón Viejo, al que se añadió el del Espolón Nuevo, que se benefició del deseo de Felipe III por verlo terminado, aunque no se culminaría hasta que en 1691 Carlos II indicase que «era una pena no se continuara éste (paseo) hasta el Puente Mayor, pues sería una obra heroica y de gran ornamento», concluyéndose a comienzos del siglo XVIII. A estas alamedas se sumaban otros paseos sobre el camino de Cigales y el de los Mártires, más allá del Puente Mayor, también del siglo XVII. ${ }^{52}$

El modelo cortesano y los precedentes de otras ciudades sirvieron de acicate a la creación y ampliación de las alamedas por la geografía peninsular durante el siglo XVII. Por ello al pensar las alamedas hay que tener en cuenta su creación y evolución, que es lenta pero constante durante el Seiscientos. Así por ejemplo en Málaga existía a comienzos del siglo XVII

50 Chueca Goitia, 1968, 228-229. Sobre su trascendencia, además de Lopezosa Aparicio, básica para todo lo relativo al Prado actualmente, Reese, 1989.

51 Merino Beato, 1989, t. 1, 100-101.

52 Ibidem, 102-108. 
un paseo de álamos que conducía al convento de la Victoria, que fue dotándose de elementos que lo convierten en una nueva alameda en $1783 .{ }^{53} \mathrm{En}$ Granada en el último cuarto del siglo XVII los espacios diáfanos del campo del Triunfo y del Príncipe se dotaron primero de un monumento de carácter religioso que dignificaba el lugar, y al tiempo acaban plantándose álamos para dar sombra y ordenar el espacio, cuya vocación urbana se transforma así radicalmente,$^{54}$ generándose de esta forma alamedas en el interior de la ciudad, como ocurrió en su día en Sevilla.

En esta ciudad la propia alameda fue transformándose, de manera que en 1614 se planteó por algunos capitulares que si el diputado de la alameda consideraba «a propósito mandar hazer algunos pollos lo mande hazer con asistencia del maestro mayor y lo que costare...». ${ }^{55}$ Este dato es muy importante, pues en la descripción de Morgado de 1587 y anteriores a este año nada se dice de bancos corridos para sentarse. De su existencia se hace eco el historiador Fermín Arana de Valflora, que indica que en su origen «se hicieron asientos correspondientes para lo que alli fueren a gozar la frescura del sitio» diferenciándolos de los ampliados y construidos bajo la orden de Ramón de Larumbe en $1764 .{ }^{56}$ Con ellos podían hacerse paradas en los paseos, recomenzando más tarde el recorrido o esperando a nuevos interlocutores. Los recorridos podían rehacerse o bien detenerse, brindando más opciones a los paseantes del lugar. Asimismo, la disposición de las calles de la alameda de Hércules en el siglo XVIII, tal y como se aprecia en el plano de Olavide de 1771, es diferente de la del siglo XVII. En el Setecientos las seis fuentes se situaban en el eje central del paseo, más ancho que las dos calles laterales. Sin embargo en el siglo XVII había dos calles grandes y una más pequeña situada al oeste de las pilas (en ese momento solo tres), pues las memorias de reparos realizadas en 1642 y 1647 nos hablan de la existencia de tres calles, dos principales que se situaban hacia la zanja este y una «angosta» arrimada a la zanja oeste de desagüe. ${ }^{57}$

53 Además de otros que se fueron conformando a lo largo de la centuria. García Gómez, 1995.

54 Acale Sánchez, 2005, 120 y 126.

55 Archivo Municipal de Sevilla (AMS), Actas Capitulares (AC), libro H-615, cabildo de 8 de marzo de 1614.

56 Arana de Valflora, 2003, 95. Álvarez Benavides, siguiendo seguramente a Valflora, indica que la autoría de estos asientos fue del conde de Barajas, aunque por lo que hemos visto parece que bien se construyeron ex novo, bien se ampliaron en 1614. Sobre los trabajos hidráulicos y reconfiguración del siglo XVIII, Fernández Chaves, 2007a.

57 Así se indica en una memoria de condiciones de reparo de 1642, en la que se indica que había que reparar «las tres regueras [...] de todo el empedrado que les falta de su material bien rematado. Y la calle angosta que está a la parte de la zanja grande la ha de limpiar y barrer como las demas». 
En esta ciudad la alameda tendría siempre su protagonismo en las discusiones municipales, puesto que el sistema hidráulico que la sostenía, el mantenimiento del arbolado y empedrado, etc., resultaban tremendamente caros. Aun así y pese a estar intervenida la hacienda municipal, nunca se vendió agua de la Fuente del Arzobispo (que la abastecía) puesto que esta posibilidad se consideraba en 1609 «en muy gran daño y perjuyzio del pueblo y de la alameda», ${ }^{58}$ idea que se repetiría de nuevo en el siglo XVIII cuando se describiera a la ciudad como:

dueña de ella [el agua] y que el nacimiento y toda el agua es de su público; este es y debe ser con prelación a todas la demás aguas y repartimientos permitidos por pura gracia... que la ciudad ha costeado la obra de las cañerías y sus arcas, y con dinero de los propios, a que tanto derecho tienen el común. ${ }^{59}$

El gran problema de esta alameda fue la llegada correcta del agua y su pasado como colector de aguas negras del norte de la ciudad. Por ello la alameda de Hércules podía llegar a ser insalubre, porque nunca perdió su condición de lugar desde donde se canalizaba buena parte de las aguas sobrantes de la ciudad, debiendo mantenerse limpias las zanjas de desagüe que recorrían el paseo longitudinalmente. ${ }^{60}$ Estos desagües solían llenarse de restos arrojados por los transeúntes y vecinos. También su propio carácter de espacio abierto «invitaba» a muchos sevillanos a acumular los desperdicios y escombros que se generaban en los rincones de aquel paseo. ${ }^{61}$ Así en 1614 los frailes de las Cuevas habían derribado unas casas tienda de su propiedad junto a una de las alcantarillas o pontezuelas que superaban el canal de desagüe junto a la calle Garbancera, arrojando allí los escombros de la obra. ${ }^{62}$ Esta costumbre llegaba a hacer rebosar de desperdicios las zanjas, bloqueando el desagüe de la zona, con consecuencias catastróficas

AMS, ACJP, libro H-672, exp. 116. Así aparece también en el mencionado cuadro expuesto en la Fundación Focus Abengoa, con una hilera central de álamos que se planta en medio de las dos columnas quedando las dos calles principales a sus lados.

58 AMS, AC, libro H-1610, cabildo de 1 de junio de 1609.

59 Fernández Chaves, 2007a, 97.

60 Un ejemplo entre otros muchos, la denuncia del alguacil Diego de Vega sobre la necesidad de limpiar y desatascar las zanjas, antes de que llegase el invierno y el trabajo se complicase, AMS, ACJP, AL, libro H-675, carp. 2, exp. 13, 26 de agosto de 1625.

61 Así en 1609 el cabildo ordenaba al diputado de la alameda, Luis Carranza, empedrar los canales de desagüe y recoger los diversos muladares que se habían formado alrededor del paseo. AMS, AC, libro H-1610, cabildo de 3 de julio de 1609.

62 AMS, AC, libro H-1615, cabildo de 20 de junio de 1614. 
en caso de inundación o fuertes lluvias. ${ }^{63}$ Por ello tampoco puede olvidarse que las alamedas también podían degradarse (la de San Pablo en Écija llegó casi a desaparecer, hasta ser reconstruida en el siglo XVIII) ${ }^{64}$ y dependían en última instancia del comportamiento de sus moradores.

El siglo XVII es para el desarrollo de las alamedas en la España moderna una época de influencias recíprocas y de emulación entre ciudades, que se acelera en las últimas décadas de siglo y se anticipa al proceso director del urbanismo borbónico. En este sentido un caso clave es el de la alameda de Valencia, que fue configurándose en la primera mitad del siglo XVII hasta que ya en los años 70 del siglo XVII se dio un claro impulso para recuperar la margen del Turia en un proyecto ordenado, que adquiere el carácter propio de una alameda ya en 1692, dedicada esencialmente al recreo de los valencianos. Este proyecto creció en extensión a partir de 1714 por iniciativa del intendente Rodrigo Caballero Llanes, creándose una nueva plaza ovalada configurada por álamos en su extremo sur, con bancos en sus extremos (la plaza frente al palacio real ya existía), realizándose más plantíos de árboles y dotándola de una calle central para peatones y dos laterales para carruajes, colocándose en su extremo cercano al palacio dos columnas con bustos de Felipe V y María Luisa de Saboya y al otro lado otra columna con el busto de Luis I, estableciéndose así un diálogo con la alameda de Hércules de Sevilla, no siendo tampoco ajena a este diálogo la erección de columnas con estatuas de personas reales. ${ }^{65}$ También se la comunicó con la ermita de Nuestra Señora de la Soledad y con un nuevo viacrucis que llevaba hasta el convento franciscano de San Juan de Ribera. ${ }^{66}$

Con el auge de las formas de religiosidad barroca y la multiplicación de conventos, ermitas y otros edificios y emplazamientos sagrados, ${ }^{67}$ el uso lúdico y recreativo de las alamedas adquiere una nueva significación en torno a su configuración total o parcial como lugares de paso hacia dichos

63 AMS, ACJP, AL, leg. H-674, carp. 1, exp. 114. En 1659 los vecinos de la calle Lumbreras habían comenzado a dejar toda la basura y escombros que producían en la puerta de la casa que daba acceso al husillo real, por lo que se ordenó quitarla «para que se pueda entrar el dia de la ocasión». AMS, ACJP, AL, libro H- 680, carp. 3, exp. 94. Fernández Chaves, 2007b.

64 Las ordenanzas sobre esta alameda, tanto su precedente de 1497 como la de 1592, prohíben la corta de árboles y la invasión del espacio por el ganado. Martín Ojeda, 1990, 229-230.

65 Como en Écija en el siglo XVIII (Aguilar Diosdado y García León, 1988), con estatuas «del actual rey de España, el príncipe y la princesa de Asturias, don Luis y el señor san Pablo, todas ellas de una execrable ejecución». Twiss, 1999, 176.

66 Gavarra Prior, 1994, 147-154. En 1797 se dividió en varios salones, al estilo del Prado, y se comunicó con un paseo bajo junto al río cercano en su concepción el paseo del Espolón de Valladolid.

67 Sobre esta proliferación y su significación social, Atienza López, 2008. 
espacios religiosos, como puede ser el caso de la alameda construida en Jaén en 1577 con álamos y dos fuentes, y que conectaba la ermita de San Cristóbal extramuros con un convento jerónimo, donde además en el siglo XVII el obispo construiría una residencia de recreo y se edificaría un convento de bernardas y otro de capuchinos ${ }^{68}$ De esta forma el carácter itinerante de las alamedas las situó en ocasiones en el rumbo hacia un espacio sagrado, donde los árboles y el agua en forma de río y/o de fuentes redimensionan su significado. No es solo la sociabilidad propia del espacio abierto y trazado, es también la peregrinación periurbana que encuentra generalmente en una ermita su punto de destino y que dota al espacio y a la sociabilidad que en él se propugna de un nuevo significado y sentido. Un claro ejemplo es el camino del Sacromonte, tachonado de fuentes, donde a comienzos del siglo XVII la calle que discurría junto al Darro ve construirse en su parte más ancha un paseo con una fuente que disponía además de una casa con un balcón para las chirimías, ${ }^{69}$ dado que aquel espacio donde tradicionalmente se celebraba la ciudad había enriquecido su significado urbano al formar parte de la nueva via sacra que llevaba hasta el Sacromonte, y esta no fue sino una más de otras alamedas y paseos que unían el espacio urbano con ermitas y espacios de devoción en la ciudad. ${ }^{70}$ Hay precedentes como la alameda y fuentes que se construyeron en Ávila camino del nuevo monasterio de los franciscanos descalzos ca. 1583, ${ }^{71}$ y pueden multiplicarse los ejemplos, como las ermitas de San Lázaro y San Sebastián que marcaban los extremos del paseo de San Sebastián en Valladolid en el siglo XVII, ${ }^{72}$ el paseo de la ermita de la Virgen del Puerto de Madrid del siglo XVIII, ${ }^{73}$ la alameda de Sigüenza ya construida a comienzos del siglo XIX que unía tres ermitas, ${ }^{74} \mathrm{o}$ la ermita construida al final de la alameda de Hércules en Sevilla, etc., crean un nuevo significado sobre estos espacios que acercan el valor de la naturaleza domesticada por el hombre a lo trascendente, pero no por esta imbricación entre los límites de lo urbano y lo natural en sí, sino porque los elementos propios de la naturaleza

68 López Cordero, 2003.

69 El enriquecimiento de estos espacios con música fue gradualmente imponiéndose y recayendo en las arcas municipales. Véase sobre este particular y en general para la ciudad de Sevilla, Bejarano Pellicer, 2013.

70 Orozco Pardo, 1985, 114-115. También, Bonet Correa, 1986. Sobre la importancia de las procesiones y estos espacios, García Bernal, 2006, 403-421.

71 López Fernández, 1982.

72 Merino Beato, 1989, t. 1, 101-102.

73 Chueca Goitia, 1968, 220, entre otros.

74 Sambricio, 1991, t. 1, 224. 
caracterizan como señales y márgenes del camino hacia el espacio sacro el paso de la cotidianeidad al espacio de retiro y valor religioso. Estos valores propios del Barroco no convirtieron las alamedas en unos vectores de religiosidad, pero sí que se superpusieron a ellas, siendo el caso granadino muy interesante, ${ }^{75}$ volviendo a aparecer en el siglo XVIII, como en el caso de la remodelación del prado de la Magdalena de Valladolid donde se retiraron árboles viejos y se creó un paseo longitudinal que unía las iglesias de la Magdalena y de San Pedro. ${ }^{76}$

\section{La generalización de paseos y alamedas en el siglo XVIII}

La decidida actuación de la monarquía en el impulso del ornato, ordenación y regulación urbanísticas durante el siglo XVIII es bien conocida. ${ }^{77}$ En este siglo el papel preponderante de Madrid en el urbanismo fue esencial, y su influjo se dejó notar tanto en la normativa al respecto que se dictaba desde la corte como en la propia modificación de la idea de ciudad que emanaba de las reformas emprendidas en ella. ${ }^{78}$ En este sentido, fue muy importante la ordenanza de intendentes y corregidores dada por Fernando VI en 1749, donde se regulaba cómo debía procederse en lo referente al ornato de poblaciones y edificios. Esta preocupación de la monarquía se plasmaba también en las edificaciones y paseos de la Corte y de aquellos que conducían a las residencias reales, y adquirió un nuevo impulso con Carlos III, quien en 1788 se preocupó por fomentar el embellecimiento de las ciudades de sus reinos, que pasaba por la ordenación de su espacio, ${ }^{79}$ construcción de paseos y plantío de árboles, conservación de los ya existentes y preocupación genuina por la mejora de la salubridad con la implementación de mejoras en los sistemas de abastecimiento y saneamiento de aguas, empedrado de calles, etc. ${ }^{80}$ Esta preocupación sobrevivió al propio monarca, puesto que formaba parte de la cultura política de muchos regidores en las ciudades, corregidores e intendentes, así como también diferentes

75 Orozco Pardo, passim.

76 Merino Beato, 1990, t. 2, 111.

77 Reguera Rodríguez, 1993; Fraile, 1997; Sambricio, 1991.

78 Cervera Vera, 1988.

79 Blasco Esquivias, 1998.

80 Lozano Bartolozzi, 2011, 224; Anguita Cantero, 1997, 122-123. Fue en la villa y corte donde más profundas y extensas fueron las reformas en este campo, cfr. Blasco Esquivias, 1992 y 1998; Sambricio, 1991. 
academias y sociedades de Amigos del País. A este interés por la «policía» ${ }^{81}$ urbana, donde los jardines y alamedas vienen a aportar una mejora en la salubridad y una clara ordenación del espacio público de ocio, se suma todo el pensamiento sobre jardinería, sus valores y su implementación tanto en los reales sitios como en quintas periurbanas, que también se aplica en la creación de estos espacios y que es propio de la cultura del siglo XVIII y el diálogo entre las tradiciones de jardinería inglesas y francesas. ${ }^{82}$

Las alamedas ya existentes se remozan y modifican. Así la alameda de Hércules dobla su dotación de fuentes y es reurbanizada en un proceso constructivo renovador, siendo estas nuevas modificaciones culminadas en $1764,{ }^{83}$ de forma que esta alameda continuaba siendo la preferida de los sevillanos como indicase el viajero Richard Twiss en $1773 .{ }^{84} \mathrm{El}$ eco de estas reformas haría revivir la alameda de Écija, casi abandonada por las invasiones del río, y reconstruida entre 1769 y $1774,{ }^{85}$ y se creará un nuevo paseo extramuros en Córdoba que formaría el núcleo de los futuros jardines de la Victoria. ${ }^{86}$ También en Sevilla la calzada de la Cruz del Campo fue arbolándose y se aprovechó el acueducto de los Caños de Carmona para su riego con la construcción de una fuente desde 1734, y se creó también el paseo de San Telmo. ${ }^{87}$ El paseo del Arenal existía desde el siglo XVI con cuatro hileras de álamos, y fue reconstruido desde 1775 al terraplenarse y elevarse el terreno como defensa frente al río, obra que se haría más ambiciosa en los años 80 con un nuevo malecón, ampliándose en torno al río otras alamedas como las Delicias, el Malecón y el famoso paseo de Bellaflor. ${ }^{88}$ Así también sucedió en Zaragoza, donde el terraplenamiento de las márgenes de los ríos Huerva y Ebro fue aprovechado para plantíos que se ampliaron en el siglo XVIII, y se potenciaron con la creación del Canal Imperial a fines de dicha centuria. ${ }^{89}$ También puede sumarse aquí el ejemplo de

81 Fraile, 1997. Pueden verse varias definiciones contemporáneas sobre el concepto en Anguita Cantero, 1997. La idea ya aparece en Vitruvio, en el capítulo X de su quinto libro, cuando habla de lo oportuno de hacer paseos en las ciudades, tras los escenario de los teatros y en torno a los templos, «porque los paseos al aire libre son muy saludables», en García Gómez, 1995, 48.

82 Añón Feliú, 1988, 129-138.

83 Fernández Chaves, 2007a.

84 Twiss, 1999, 211-212. Sobre la alameda de Sevilla como espacio de sociabilidad, Fernández Chaves, 2007a.

85 Aguilar Diosdado y García León, 1988, 20-23.

86 López Ontiveros, 2009, 150.

87 Bonet Correa, 1978, 298.

88 Ollero Lobato, 2004, 243-247.

89 López González, 1977, 281-302. 
Burgos $^{90}$, Valladolid ${ }^{91}$ o Soria, donde la Sociedad Económica de Amigos del País de Soria creó el paseo y plantío del Mirón en 1785, que se amplió en $1790^{92}$, y otro tanto sucedió en ciudades medias como Jerez de la Frontera, ${ }^{93}$ o Salamanca, al menos desde $1783 .{ }^{94}$ En esta misma línea de crecimiento en Málaga se crea la alameda del Prado en 1783, que marcará un hito en la expansión de la ciudad extramuros. ${ }^{95}$ Resulta muy interesante considerar la importancia de los diversos proyectos que se fueron planteando en Málaga para mejor aprovechar las aguas del Guadalmedina y evitar por un lado las avenidas y por otro utilizar ese agua para el riego, la industria y, cómo no, abastecimiento de las alamedas y paseos arbolados. Desde su finalización en 1786, fue transformándose su entorno y constituyendo un imán para la población, al tiempo que se prolongaba su trazado sobre la antigua alameda de Capuchinos y la de Olletas, entre otras, aprovechándose cuando era posible del nuevo acueducto de San Telmo, que había multiplicado desde hacía bien poco (1784) las posibilidades de contar con agua corriente extra e intramuros. ${ }^{96}$ En Granada a la alameda cercana a la ermita junto al Genil se añaden nuevos espacios de paseo tras la remodelación y acondicionamiento del curso del río acometido a mediados del siglo XVIII. ${ }^{97}$ El caso de Granada como el de Málaga es arquetípico de la renovación de esta centuria: el espacio de las alamedas y paseos aumenta, mejora en la calidad de su arbolado y fuentes, y viene a ocupar un lugar preferente en el planeamiento urbano. ${ }^{98}$

90 Iglesias Rouco, 1978, 49-50; Sambricio, 1991, t. 1, 237-241.

91 Merino Beato, 1990, t. 2, 97-113. Se utilizó mano de obra de entre los presos de las cárceles de la ciudad, y se planteó la obra como una forma de estimular la economía de la urbe, creándose un auténtico cinturón verde sobre las murallas, Sambricio, 1991, t. 1, 225-229; Merino Beato, 1990, t. 2, 103. Se creó además el paseo de Floridablanca y se plantaron árboles «útiles» como moreras. Sambricio, 1991, t. 1, 232-237; Merino Beato, 1990, t. 2, 105-108; Brasas, 1979.

92 Rupérez Almajano, 1987, 160 y 170. Además la Sociedad construyó tres nuevas fuentes de agua que se añadían a la única existente en la ciudad. Se dio empleo también a campesinos sin oficio. Sambricio, 1991, t. 1, 240.

93 Aroca Vicenti, 2002, 150-157.

94 Rupérez Almajano, 1987, 147-162, recogido en Lozano Bartolozzi, 2011, 226.

95 García Gómez, 1995.

96 Sobre el mismo, Davó Díaz, 1986. Sobre las necesidades de agua de las alamedas de Málaga y la construcción de más fuentes: García Gómez, 1995, 163-168; Camacho Martínez, 1987.

97 Acale Sánchez, 2005, 160-166. Sobre su evolución posterior, Isac, 2010, 210-214.

98 Acale Sánchez, 2005, 170. Esta idea de control de la población puede ponerse en relación con los motines de Madrid de 1766 entre los que se contaba el plan de limpieza de Sabatini y la decisión del conde de Aranda como Gobernador del Consejo de Castilla de renovar el Prado «como obsequio a las masas populares... Aranda ponía de relieve el recreo, no la limpieza y la autodisciplina» en palabras de Reese, 1989, 6. Sobre las medidas de control social y el espacio de la ciudad, Fraile, 1997, toda la obra, y especialmente, $75-90$. 
Esta multiplicación de alamedas se repite a lo largo y ancho de la Península. En la propia ciudad de Madrid se aumenta la extensión del Prado hacia Atocha y se crean otros paseos hacia el Manzanares como el de la ermita de la Virgen del Puerto, entre otros. ${ }^{99}$ Estos serán los espacios de sociabilidad por excelencia, donde las damas y sus cortejos se encontraban y daban cita. ${ }^{100}$ Pero también los majos y otros personajes que representaban la moda y las maneras «nacionales», generándose esas tensiones entre unos y otros ${ }^{101}$ que desembocaban en violencias como en el caso de Sevilla, donde a finales del siglo XVIII los regidores de la ciudad disponían que debía controlarse el acceso de personas no indicadas a estos paseos:

Concurriendo en las noches de verano para descargo y alivio muchas gentes de todas clases al paseo de la alameda, a la Alamedilla de la Puerta de Triana, al puente y gradas de la Iglesia Catedral, como asimismo a la circunferencia de la Lonja, y otros sitios, ha llegado a entender su Señoría que algunos jóvenes con poca reflexión y otros sujetos de mala crianza y falta de policía, han insultado a varias personas de ambos sexos con expresiones y gestiones importunas e indecentes sobre los trajes, adornos y manejo; y siendo uno de los puntos más delicados e importantes, se advierte por regla general, que a quien se le aprenda en fragante o se le justifique que ha incurrido en semejantes desatenciones y excesos se le formará sumaria, y tratará como a un perturbador de la quietud pública, procediéndose sumariamente a lo que exijan las circunstancias, y aún a otros remedios y entre ellos el de prohibir los embozos con que intenten ocultarse... a fin de que de essa suerte se pongan los paseos en el grado de atención y en esta libertad que los hace apreciables, y se recomienda muy particularmente la vigilancia a los Alcaldes de Quartel, a los de Barrios, escribanos y ministros subalternos. ${ }^{102}$

Nótese aquí la tensión entre majos y petimetres, los problemas de los embozados, tan característicos de los altercados de orden público del siglo XVIII español, y la concepción de estos espacios como lugares de libertad, que como dijera Jovellanos:

Ejercicios de fuerza, destreza, agilidad o ligereza; bailes públicos, lumbradas o meriendas, paseos, carreras, disfraces o mojigangas; sean los que fueren, todos serán buenos e inocentes con tal que sean públicos. Al buen juez toca proteger al pueblo en tales pasatiempos, disponer y adornar los lugares destinados para ellos, alejar de allí cuanto pueda turbarlos y dejar que se entregue libremente al esparcimiento y alegría... nunca pierda de vista que el pueblo que trabaja, como ya hemos advertido, no necesita que el gobierno le divierta, pero sí que le deje divertirse. ${ }^{103}$

99 Añón Feliú, 1988, 159-161.

100 Molina Martín, 2013, 326-342.

101 Martín Gaite, 1981; Molina Martín, 2013.

102 Archivo Histórico Nacional, Consejos, leg. 904, exp. 8. La cursiva es mía.

103 Jovellanos, 1858, 453. 


\section{Conclusiones}

La creación de las alamedas en la España Moderna, al menos desde el siglo XVI, respondió a un doble diálogo con la tradición clásica y con las actuaciones habidas en otros puntos de Europa, y trascendió las lógicas locales para convertirse en un equipamiento urbano cada vez más demandado y solicitado, generándose un modelo impulsado por la monarquía en el que tuvieron también responsabilidad algunos cabildos municipales y que se trasladaría en los espacios americanos y filipino. Terminó por convertirse en el siglo XVIII en uno de los elementos más importantes del ordenamiento de espacios urbanos periféricos situados extramuros y cerca (aunque no siempre) de un cauce fluvial.

Las ideas de «ornato» y «honra de la ciudad» se van desarrollando en un proceso de concepción de lo urbano que va siendo cada vez menos local y más europeo y americano, concretándose y definiéndose estas ideas en el siglo XVIII en el concepto de policía, que adquiere una significación polisémica, en el que se cuenta la necesidad de organizar la población, los recursos y el territorio para fomentar la riqueza nacional y por tanto la felicidad de los súbditos. Estas necesidades se proyectarán lógicamente sobre el espacio urbano, ${ }^{104}$ que a partir de la ordenanza de 1768 es dividido en cuarteles y barrios, primero en las ciudades sede de tribunales, y luego en otras a petición propia, ${ }^{105}$ poniéndose el acento en el paisaje higienista compuesto por «paseos, alamedas, parques, plazas, jardines botánicos, campos de experimentación agrícola, huertas...». ${ }^{106}$ En dicho proceso fue muy importante la proyección de estos valores por parte de la monarquía y su asunción como institución rectora de los mismos en sus aplicaciones urbanas, siendo Madrid el caso paradigmático. La originalidad del siglo XVIII en materia de urbanismo pasó por canalizar el impulso regio más allá de los espacios de representación urbanos de la monarquía para trascender todos los elementos de su tejido, de manera que

En la propia idea de embellecimiento se dio, sin embargo, una progresiva evolución que fue desde la valoración del espacio del Príncipe a definir propuestas en lo que ya se aceptaba era el caos. Se actuó, por ello, en un espacio heterogéneo y se definió un

104 Anguita Cantero, 1997, 112-116; Reguera Rodríguez, 1993.

105 Anguita Cantero, 1997, 118-119, siguiendo a Guillamón, 1980. Para el caso de Sevilla véase, Hernández Navarro, 2006; Campese Gallego, 2005.

106 Reguera Rodríguez, 1993, 112 y ss. 
único proyecto urbano consistente en la creación de paseos... se analizó que significaba el concepto límite y una idea nueva (el Paseo) sustituyó tanto a terrazas, fosos, muros, murallas..., como a la vía o eje urbano definido en las propuestas barrocas... ahora se concibe un conjunto de operaciones que se encuadran con la voluntad de organizar arboledas en los caminos que conducen a las poblaciones (Barcelona, Tarragona, Alicante, Zaragoza, Madrid) siguiendo al idea que difunde Antonio Ponz, cuando comenta cómo esta medida debía imponerse por las autoridades eclesiásticas a los párrocos, con vistas a que éstos, desde el púlpito... incitasen y estimulasen a los vecinos al plantío de árboles y organización urbana de alamedas. ${ }^{107}$

En efecto, Antonio Ponz fue un firmísimo defensor de la multiplicación de árboles en el país, tanto por su efecto benefactor en la agricultura y en el clima como por razones económicas (combustible, material de construcción...), y alababa la creación de arboledas en caminos y paseos en Valladolid, Ávila, Burgos, Toledo, pues:

El deleite que se afirmaba regalarían estos paseos debería vincularse a las nuevas formas de relación y comportamiento social que se establecieron en estas fechas, a una civilidad que ya coetáneamente se consideró menos ruda que el trato en el pasado y que se abrió a renovados placeres de la sensibilidad aunque decorosos. Los árboles, pues no solo parecían purificar el aire, sino también ser un elemento del escenario apropiado para el desahogo y el entretenimiento del hombre refinado. ${ }^{108}$

Pero como hemos visto no es solo la influencia de la corte en el siglo XVIII, sino la de Felipe II en el Quinientos y junto a este primer interés la potenciación de una mentalidad urbanística que estaba definiéndose al menos desde el siglo XVI, y que encuentra un eco político al más alto nivel de la edilicia y urbanística regias, no debiéndose además perder de vista en este proceso la sana emulación que se dio, como hoy, entre las élites de las diversas ciudades por alcanzar el modelo de ornato y embellecimiento además de comodidad propuestos por Madrid.

En las alamedas se proyecta y comparte el espacio del jardín, que tradicionalmente había quedado confinado en huertas y jardines de palacios y conventos. Esto es, la existencia de estos lugares que aportaban sin duda una salubridad fundamental a las ciudades de la Edad Moderna respondían también a un ideal de privacidad que se proyecta con fuerza sobre la

107 Sambricio, 1991, t. 1, 197, 200-202. Así por ejemplo se describía el prado de la Magdalena de Valladolid, entre los ríos Esgueva y Pisuerga, como «lleno de umbrías y de gran recreación», considerado por Pinheiro da Veiga como «un bosque de álamos» en el que había además sauces y chopos. Merino Beato, 1989, t. 1, 102.

108 Crespo Delgado, 2012, 164. Solo matizar aquí que estas formas de sociabilidad no eran precisamente nuevas. 
ciudad y que por tanto es «exportado» del interior doméstico al espacio urbano, trasladando todos los matices positivos que conllevaba su existencia en las casas al «común» que no disponía de estos espacios. Ciudades como Sevilla, Granada, Madrid o Valladolid contaban con un importante número de jardines y huertas privadas que hacían del tejido urbano una trama transida de distintas tonalidades de verdes, y ello no debe olvidarse cuando se tienen en cuenta las deficientes condiciones de higiene imperantes en las urbes de la modernidad. No obstante el crecimiento demográfico del siglo XVIII elevó los edificios y tendió a colmatar las manzanas con la fábrica de los mismos, haciéndose más necesarios los paseos y espacios verdes en las ciudades, ${ }^{109}$ ocupando cada vez más el limes entre lo urbano y lo rural, con lo que, como sucedía con el paseo de Floridablanca de Valladolid. ${ }^{110}$ Entra en juego el gran desarrollo de las alamedas y paseos del siglo XVIII que hemos comentado, donde el desarrollo de estos espacios es heredero del interés por los jardines de los dos siglos anteriores, que se desarrolla en la estética de lo pintoresco y se independiza de la arquitectura desde Laugier a Le Nôtre. Adquiere así la naturaleza un espacio propio en las ciudades, desarrollándose en España «la voluntad de insertar amplios pulmones verdes en el interior de los tejidos urbanos» ${ }^{111}$ como se evidencia en las ciudades que hemos ido visitando. Pero también estos pulmones verdes tuvieron un gran desarrollo en los entornos de las ciudades, construyendo una relación nueva de los recintos urbanos con el espacio circundante.

Este borde arbóreo de las ciudades las separa a través de la naturaleza domesticada de lo que ya no es urbano o incluso de lo suburbano, como proponía sobre una ciudad de nueva traza el ingeniero Benito Bails en sus Elementos de matemática de 1783:

alrededor de la Ciudad haríamos tres viales o calles de árboles, el de enmedio ancho para los carruajes; y los de los lados, más angostos para la gente de pie. Más allá de estos tres viales plantaríamos los arrabales, adonde echaríamos todos los oficios mecánicos que causan mal olor, o hacen ruido, los lavaderos, las casas donde se alquilan sillas de posta, coches de camino, y también los mataderos con las cuadras que necesitan. ${ }^{12}$

109 Un caso claro de esta nueva necesidad es el de la conexión urbanística entre la Murcia intramuros y la alameda del Carmen en el siglo XVIII. Martínez Ripoll, 1977. Sobre las distintas alamedas y paseos de esta ciudad, Peñafiel Ramón, 2007 y 2006, 21-53.

110 Sambricio, 1991, t. 1, 234.

111 Gravagnuolo, 1998, 29-31.

112 Fraile, 1997, 108. Desde luego la creación de una alameda formaba parte consustancial de nuevas ciudades como la de El Ferrol creada por Julián Sánchez Bort en 1763, la mayor de toda Galicia en aquel periodo. Cardesín, 2004. 
Y a su vez, este borde arbóreo es el mismo que se pensaba para la división intraprovincial de la España imaginada de Sinapia: «separadas unas de otras mediante fosas, doble fila de árboles y pirámides de piedra o ladrillo», y lo mismo para el límite de las ciudades, «las ciudades (también de traza cuadrada) se describían circundadas por paseos arbolados (con lo que se impedía su crecimiento)». Ello lleva a Carlos Sambricio a indicar que:

$\mathrm{Al}$ releer las características que se atribuyen a las provincias, partidos o villas se advierte como la forma de marcar límites (utilizar el arbolado construyendo paseos a modos de alamedas, urbanizando la naturaleza o disponiendo pirámides de ladrillo en los puntos de encuentro de los caminos) entronca lo que en la Francia de la segunda del XVIII se denominó le devoir d'embellir, planteamiento en todo punto ajeno al urbanismo de finales del XVII. Lo que no había aparecido ni el XVII ni tampoco durante la primera mitad del XVIII se hacía presente en la segunda mitad del siglo en Francia y España, pudiendo relacionar lo comentado con los múltiples proyectos de alamedas que aparecen en la España ilustrada (Paseo del Prado en Madrid, Ramblas en Barcelona, Arenal en Bilbao, alameda en Málaga, Paseo del Espolón en Burgos...), en las propuestas para sustituir los muros defensivos por paseos arbolados que limitaban la población (Barcelona, San Carlos en Cádiz, Madrid, Valladolid...). ${ }^{113}$

El profesor Sambricio llega pues a la conclusión de que la multiplicación de las alamedas respondía a una mímesis de lo actuado en Madrid, que arrastraba tras de sí otras operaciones urbanas de embellecimiento y rectificación de espacios, canalización de aguas, del tráfico de coches y personas, etc., impulsándose modificaciones de la infraestructura urbana en lo que Lavedan entendía como el descubrimiento de los problemas urbanos, ${ }^{114}$ por lo que podemos concluir que la construcción y/o ampliación de las alamedas en el Setecientos ya no suponía solo el consiguiente aumento de las dotaciones de agua corriente urbanas, sino también estimulaban todo un programa que respondía a la mentalidad urbanística de corte ilustrado imperante en la segunda mitad del siglo XVIII, y, en última instancia, se perseguía también la modificación tanto de infraestructuras como de la propia trama urbana. ${ }^{115}$ Para los viajeros británicos el paseo constituía un rasgo distintivo de la sociabilidad española, opinando algunos que «parece que en España, todo pueblo de una cierta consideración debe tener un paseo público»; y en efecto, el respeto a esta costumbre por nobles, prelados y gente corriente era general y así lo recogen estos viajeros, que, gustaban de las

113 Sambricio, 2014.

114 Sambricio, 1991, t. 1, 229 y 240

115 Idea que preside la obra de Sambricio, 1991, t. 1, 241-251, y sobre a los ensanches 259-397. 
alamedas pero criticaban que fueran el único marco de actividad social no urbana, viviendo sus habitantes de espaldas al campo. ${ }^{116}$

La alameda es pues una creación plenamente original del Renacimiento urbano del siglo XVI, que reorganiza espacios periurbanos previamente empleados de forma espontánea para el desarrollo de lo lúdico, lo profano y también lo sacro, además de lo deportivo, y que exportan el jardín y la naturaleza sobre el plano ortogonal punteado de fuentes y estatuas y organizando la espontaneidad social desorganizada que empleaba esos espacios entre la ciudad y el campo. ${ }^{117}$ Estas primeras alamedas, surgidas de las necesidades higiénicas claramente sentidas ya a finales de la Edad Media, donde corre el agua y el aire, fueron transformándose y adquirieron una nueva significación con el paso de los tiempos, modificándose o potenciándose según los casos su carácter lúdico, sacro, etc., y estallando gracias a la monarquía pero también al impulso de algunas élites locales en una profusión sin precedentes por todas las ciudades y localidades de la Península al convertirse en un equipamiento concebido como básico y necesario, mucho más que otros íntimamente relacionados con él, como el alcantarillado, alumbrado, etc., ${ }^{118}$ y quedando además fijos en la trama conceptual urbana como loci amoeni donde se desarrollará el topos caballeresco en la literatura y la visión de las ciudades. ${ }^{119} \mathrm{Su}$ crecimiento se debe ahora a criterios estéticos entre los que se conservan los valores de sociabilidad y de disfrute de la naturaleza «suburbana», pero también se someten a la «utilidad» y el «beneficio» social y económico que generan o se asocian a estos espacios, lejos de una contemplación que no fuese dirigida y reglada a fines que están por encima del individuo. Su éxito continuaría en el siglo XIX, ${ }^{120}$ como evidencia la evolución del Prado en Madrid

116 Freixa, 1993, 87-89 y 105, para las dos citas.

117 Estudios tan valiosos como el de García Gómez atribuyen al siglo XVIII la salida de los espacios verdes del mundo privado y la multiplicación de paseos públicos y alamedas, cuando es claro que la creación de estos espacios ya estaba desarrollándose al menos desde la segunda mitad del siglo XVI. García Gómez, 1995, 47.

118 En el viaje del clérigo de Priego, Diego Alejandro de Gálvez de 1755, este valora positivamente las alamedas como las de Burgos junto a las murallas, Logroño, la «gran y espesa alameda con una hermosa fuente en medio» entre la ciudadela y la ciudad, o en la Barceloneta indicaba, «se continuará la explanada con una gran alameda y paseo entre esta nueva población que le llaman Bacerloneta y el fuerte de San Carlos... es la cosa mas pulida que se puede imaginar ver este nuevo pueblo su igualdad, derechas líneas...». Pérez Calero, 1986, t. 1, 148-149.

119 Paya, 2014, 4-6.

120 Rodríguez Romero y Prieto González, 1997; Prieto González y Rodríguez Romero, 1998. Sobre las reformas josefinas, tanto en la trama como en la potenciación de alamedas, por ejemplo en Valencia, Sambricio, 1991, t. 1, 578-601. 
o en lugares pequeños como Palencia, ${ }^{121}$ y el crecimiento urbano engulliría a muchas alamedas que sobrevivieron transmutadas en «bulevares» o en espacios ajardinados mutilados (como Sevilla), en vías urbanas desprovistas de toda significación de jardín, precisamente porque estos espacios también tenían una vocación nueva de ejes directores del crecimiento urbano, ${ }^{122}$ como efectivamente lo fueron muchos de ellos, haciendo tan cotidiana su presencia y más o menos conservada en su esencia, que hasta hace bien poco no se ha dado un estudio sistemático de las mismas, y del que estamos seguros se continuará obteniendo abundantes frutos.

Recibido el 18 de junio de 2015 Aceptado el 1 de septiembre de 2015

\section{Bibliografía}

Acale Sánchez, Fernando: Plazas y paseos de Granada. De la remodelación cristiana de los espacios musulmanes a los proyectos de jardines en el Ochocientos, Granada, Universidad de Granada/Editorial Atrio, 2005.

Aguilar Diosdado, Abilio y García León, Gerardo: Reseña histórica del Paseo de San Pablo, Écija, Ayuntamiento de Écija, 1988.

Alario Trigueros, María Teresa: «Los jardines del salón de Palencia: un espacio entre la naturaleza y la cultura», Boletín del Seminario de Estudios de Arte, BSAA Arte, LXXV, Valladolid, 2009, 273-284.

Albardonedo Freire, Antonio: «Las trazas y construcción de la Alameda de Hércules», Laboratorio de Arte, 11, Sevilla, 1998, 135-165.

Albardonedo Freire, Antonio: El urbanismo de Sevilla durante el reinado de Felipe II, Sevilla, Guadalquivir, 2002.

Anguita Cantero, Ricardo: Ordenanza y policía urbana. Los orígenes de la reglamentación edificatoria en España (1750-1900), Granada, Universidad, 1997.

Añón Feliú, Carmen: Carlos III. Alcalde de Madrid, 1788-1988, Madrid, Ayuntamiento de Madrid, 1988, 129-174.

Arana de Valflora, Fermín: Compendio histórico descriptivo de la Muy Noble y Muy Leal Ciudad de Sevilla, Sevilla, Fundación Aparejadores, 2003 [1766].

Aroca Vicenti, Fernando: Arquitectura y urbanismo en el Jerez del siglo XVIII, Jerez de la Frontera, Centro Universitario de Estudios Sociales, 2002.

Atienza López, Ángela: Tiempos de conventos. Una historia social de las fundaciones en la España Moderna, Madrid, Marcial Pons, 2008.

121 Alario Trigueros, 2009.

122 Sambricio, 1991, t. 1, 241.

Anu. estud. am., 72, 2, julio-diciembre, 2015, 453-486. ISSN: 0210-5810. DOI: 10.3989/aeamer.2015.2.03 
Assunto, Rosario: Ontología y telelogía del jardín, Madrid, Tecnos, 1991.

Bejarano Pellicer, Clara: El mercado de la música en la Sevilla del Siglo de Oro, Sevilla, Universidad de Sevilla, Fundación Focus-Abengoa, 2013.

Blasco Esquivias, Beatriz: Arquitectura y urbanismo en las Ordenanzas de Teodoro Ardemans para Madrid, Madrid, Ayuntamiento de Madrid, 1992.

Blasco Esquivias, Beatriz: ¡Agua va! La higiene urbana en Madrid (1561-1761), Madrid, Caja Madrid, 1998.

Bonachía Hernando, Juan Antonio: «"Más honrada que ciudad de mis reinos...”: La nobleza y el honor en el imaginario urbano (Burgos en la Baja Edad Media)», en Bonachía Hernando, Juan Antonio (coord.), La ciudad medieval. Aspectos de la vida urbana en la Castilla bajomedieval, Valladolid, Universidad de Valladolid, 1996, 169-212.

Bonet Correa, Antonio: Andalucía Barroca. Arquitectura y urbanismo, Barcelona, Ediciones Polígrafa, 1978.

Bonet Correa, Antonio: «Entre la superchería y la fe: el Sacromonte de Granada» en Bonet Correa, Antonio, Andalucía monumental. Arquitectura y ciudad del Renacimiento y el Barroco, Sevilla, Eds. Andaluzas Unidas, 1986, 33-52.

Brasas, José Carlos: «El urbanismo del siglo XVIII en Valladolid: el nuevo paseo de Floridablanca», Boletín de arte y arqueología de la Universidad de Valladolid, XLV, Valladolid, 1979, 507-514.

Braunfels, Wolfgang: Urbanismo occidental, Madrid, Alianza, 1983.

Camacho Martínez, Rosario: «Viaje de agua, camino de pan: La fuente y puente de rey en Churriana (Málaga)», Boletín de Arte, 8, Málaga, 1987, 61-82.

Campese Gallego, Fernando Javier: La representación del Común en el Ayuntamiento de Sevilla, Sevilla, Universidad de Sevilla/Universidad de Córdoba, 2005.

Cardesín, José M.: «"A tale of two cities": the memory of Ferrol, between the Navy and the working class», Urban History, 31-3, Cambridge, 2004, 329-356.

Castillo de Bobadilla, Jerónimo: Política para corregidores y señores de vasallos en tiempo de paz y de guerra, Madrid, Real Compañía de Impresores y Libreros del Reino, 1775 [1597].

Cervantes Saavedra, Miguel de: Novelas ejemplares, ed. a cargo de Jorge García López, Barcelona, Crítica, 2001 [Madrid, Juan de la Cuesta, 1613].

Cervera Vera, Luis: «Normas para las mejoras urbanas en el Madrid de Carlos III y algunas disposiciones precedentes», en Sambricio, Carlos (ed.), Carlos III. Alcalde de Madrid, 1788-1988, Madrid, Ayuntamiento, 1988, 235-264.

Chueca Goitia, Fernando: «La época de los Borbones», en García Bellido, Antonio et al., Resumen histórico del urbanismo en España, Madrid, Instituto de Estudios de Administración Local, 1968, 213-248.

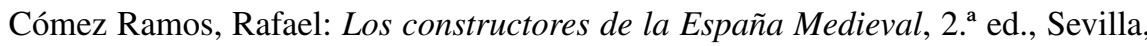
Universidad de Sevilla, 2006. 
Crespo Delgado, Daniel: Un viaje para la Ilustración. El Viaje de España (17721794) de Antonio Ponz, Madrid, Marcial Pons Ediciones de Historia, 2012.

Davó Díaz, Pedro José: El acueducto de San Telmo, Málaga, Diputación, 1986.

Durán Montero, María Antonia: «La Alameda de los Descalzos de Lima y su relación con las de Hércules de Sevilla y la del Prado de Valladolid», en Actas de las III Jornadas de Andalucía y América, Sevilla, Escuela de Estudios Hispano-Americanos, 1985, t. 2, 171-182.

Fernández Chaves, Manuel F.: «El agua en la Alameda de los Hércules en el siglo XVIII: gestión de un recurso para la organización del espacio», Archivo Hispalense, 273-275, XC, Sevilla, 2007a, 77-111.

Fernández Chaves, Manuel F.: «Hábitos de la naturaleza y costumbres de la ninfa "indolencia" en Sevilla: Río y husillos», en Núñez Roldán, Francisco (coord.), Ocio y Vida Cotidiana en el mundo hispánico en la Edad Moderna, Sevilla, Universidad de Sevilla, 2007b, 755-767.

Fernández Chaves, Manuel F.: Los Caños de Carmona y el abastecimiento de agua en la Sevilla moderna, Sevilla, Emasesa Metropolitana, 2011.

Fernández Chaves, Manuel F.: Política y administración del abastecimiento de agua en Sevilla durante la Edad Moderna, Sevilla, Diputación, 2012.

Fraile, Pedro: La otra ciudad del Rey. Ciencia de policía y organización urbana en España, Madrid, Celeste, 1997.

Freixa, Consol: Los ingleses y el arte de viajar. Una visión de las ciudades españolas en el siglo XVIII, Barcelona, Ediciones del Serbal, 1993.

García Bernal, José Jaime: El fasto público en la España de los Austrias, Sevilla, Universidad de Sevilla, 2006.

García Cano, María Isabel: La Córdoba de Felipe II. Gestión financiera de un patrimonio municipal e intervención política de una monarquía supranacional, Córdoba, Universidad de Córdoba, 2003.

García Gómez, Francisco: «La Alameda de Málaga y el Salón del Prado. Estudio comparativo», Baética, 15, Málaga, 1993, 7-20.

García Gómez, Francisco: Los orígenes del urbanismo moderno en Málaga: el Paseo de la Alameda, Málaga, Universidad de Málaga, 1995.

Gavarra Prior, Juan J.: «El paseo de la Alameda de Valencia. Historia urbana de un espacio para la recreación pública (1664-1994)», Ars Longa, 5, Valencia, 1994, 147-157.

Gravagnuolo, Benedetto: Historia del urbanismo en Europa. 1750-1960, Madrid, Akal, 1998.

Guidoni, Enrico y Marino, Angela: Historia del urbanismo. El siglo XVI, Madrid, Instituto de Estudios de Administración Local, 1985.

Hernández Navarro, Francisco Javier: Sevilla limpia e iluminada. El padrón de fincas urbanas de 1795, Sevilla, Fundación Aparejadores, 2006.

Iglesias Rouco, Lena S.: Arquitectura y urbanismo en Burgos bajo el Reformismo Ilustrado (1747-1813), Burgos, Caja de Ahorros Municipal, 1978. 
Isac, Ángel: «El verde sin norma. Los espacios públicos ajardinados en la ciudad del siglo XIX. Un caso de estudio: Granada», en Anguita Cantero, R. y Huetz de Lemps, X. (eds.), Normas y prácticas urbanísticas en ciudades españolas e hispanoamericanas (Siglos XVIII-XXI), Granada, Universidad, 2010, 201-228.

Jovellanos, Gaspar Melchor de: «Memoria para el arreglo de la policía de los espectáculos y diversiones públicas y sobre su origen en España» [1796], en Obras publicadas e inéditas, ed. de Cándido Nocedal, Biblioteca de Autores Españoles, 46, Madrid, M. Rivadeneira, 1858, 480-502.

Lawrence, Henry W.: City Trees: A Historical Geography from the Renaissance through the Nineteenth Century, Charlotesville, University of Virginia Press, 2008.

Lleó Cañal, Vicente: Nueva Roma. Mitología y Humanismo en el Renacimiento sevillano, Madrid, Centro de Estudios Europa Hispánica, 2012.

López Álvarez, Alejandro: Poder, lujo y conflicto en la corte de los Austrias. Coches, carrozas y sillas de mano, Madrid, Polifemo, 2007.

López Cordero, Juan Antonio: Jaén tras la muralla (Primera Expansión, 15001950), Granada, Caja General de Ahorros de Granada, 2003. Consultado en línea 28-V-2015 http://pegalajar.org/barriosjaen/jaenmur.htm.

López Fernández, María Teresa: «La construcción del convento de San Antonio en Ávila y las fuentes de su alameda», Boletín del Seminario de Estudios de Arte y Arqueología, BSAA, 48, Valladolid, 1982, 367-370.

López González, Juan Jaime: La ciudad de Zaragoza a finales del siglo XVIII (1780-1792), Zaragoza, Institución Fernando el Católico, 1977.

López Guzmán, Rafael: Tradición y clasicismo en la Granada del siglo XVI. Arquitectura civil y urbanismo, Granada, Diputación Provincial, 1987.

López Ontiveros, Antonio: «Evolución urbanística de Córdoba en los siglos XVII y XIX según la literatura viajera», en Escobar Camacho, José María et al., La ciudad de Córdoba: origen, consolidación e imagen, Córdoba, Universidad de Córdoba, 2009, 133-216.

Lopezosa Aparicio, Concepción: El Paseo del Prado de Madrid: arquitectura y desarrollo urbano en los siglos XVII y XVIII, Madrid, Fundación de Apoyo a la Historia del Arte Hispánico, 2005.

Lozano Bartolozzi, María del Mar: Historia del urbanismo en España. Volumen II, Siglos XVI, XVII y XVIII, Madrid, Cátedra, 2011.

Martín Gaite, Carmen: Usos amorosos del dieciocho en España, Barcelona, Lumen, 1981.

Martín Ojeda, Marina: Ordenanzas del concejo de Écija (1465-1600), Écija, Ayuntamiento de Écija, Diputación de Sevilla, 1990.

Martínez Ripoll, Antonio: «Urbanismo utópico dieciochesco. La nueva plaza de la Alameda del Carmen en Murcia, por Jaime Bort», Anales de la Universidad de Murcia. Filosofía y Letras, 36, 3-4, Murcia, 1977, 297-324. 
Merino Beato, María Dolores: Urbanismo y arquitectura de Valladolid en los siglos XVII y XVIII, Valladolid, Fundación Municipal de Cultura, 1989-1990, tomo 1, siglo XVII, tomo 2, siglo XVIII.

Molina Martín, Álvaro: Mujeres y hombres en la España ilustrada. Identidad, género y visualidad, Madrid, Cátedra, 2013.

Morales Padrón, Francisco (ed.): Memorias de Sevilla. (Noticias sobre el siglo XVII), Córdoba, Monte de Piedad y Caja de Ahorros de Córdoba, 1981.

Morgado, Alonso: Historia de Sevilla, Sevilla, Libanó, 2001 [1587].

Ollero Lobato, Francisco: Cultura artística y arquitectura en la Sevilla de la Ilustración (1775-1808), Sevilla, Caja San Fernando, 2004.

Olmedo Sánchez, Yolanda Victoria: Arquitectura y urbanismo en la Granada del Barroco tardío (1667-1750), Córdoba, Universidad de Córdoba, 2002.

Orozco Pardo, José Luis: Christianópolis: urbanismo y contrarreforma en la Granada del 600, Granada, Diputación Provincial, 1985.

Paya, Laurent: «Les alamédas de l'Empire Espagnol durant la Renaissance: un ensemble singulier et cohérent de promenades arborées», Le Verger Bouquet 05, Tours, janvier 2014, 1-19.

Peñafiel Ramón, Antonio: Los rostros del ocio: paseantes y Paseos en la Murcia del Setecientos, Murcia, Universidad de Murcia, 2006.

Peñafiel Ramón, Antonio: «Paseos públicos, paseantes y petimetres en la Murcia del Setecientos», en Núñez Roldán, F. (coord.), Ocio y Vida Cotidiana en el mundo hispánico en la Edad Moderna, Sevilla, Universidad de Sevilla, 2007, 605-616.

Pérez Calero, Gerardo: «Los viajes como fuente histórico artística: a propósito del itinerario geográfico de Diego Alejandro de Gálvez, de 1755», VI Congreso Español de Historia del Arte CEHA. Los caminos y el arte, Santiago de Compostela, Universidad de Santiago de Compostela, 1986, t. 1, 141-153.

Pleguezuelo Hernández, Alfonso: Cayetano de Acosta (1709-1778), Sevilla, Diputación de Sevilla, 2007.

Prieto González, José M. y Rodríguez Romero, Eva J.: «"Caprichos” en el jardín. Ficción y realidad en la escenografía de los ámbitos de recreo público decimonónicos», Archivo Español de Arte, LXXI, 284, Madrid, 1998, 391-406.

Reese, Thomas F.: «Hipódromos, carros, fuentes, paseantes y diversión pública en la España del siglo XVIII: Un programa agrario y de la antigüedad clásica para el Salón del Prado», en IV Jornadas de Arte. El arte en tiempo de Carlos III, Madrid, CSIC, 1989, 1-47.

Reguera Rodríguez, Antonio: Territorio ordenado, territorio dominado. Espacios, políticas y conflictos en la España de la Ilustración, León, Universidad, 1993.

Rodríguez Romero, Eva J. y Prieto González, José M.: «Haciendo el jardín de las delicias. Ficción y realidad en relación a los ámbitos de recreo público decimonónicos», Archivo Español de Arte, LXX-280, Madrid, 1997, 397-418. 
Ruiz Hernando, José Antonio: Historia del urbanismo en la ciudad de Segovia del siglo XII al XIX, Segovia, Diputación Provincial, 1982.

Rupérez Almajano, María Nieves: La Sociedad Económica de Amigos del País de Soria (1777-1809). Estudio institucional, Soria, Diputación Provincial, 1987.

Sabaté Bel, Joaquín: «Los reglamentos urbanos de la arquitectura», en Anguita Cantero, R. y Huetz de Lemps, X. (eds.), Normas y prácticas urbanísticas en ciudades españolas e hispanoamericanas (Siglos XVIII-XXI), Granada, Universidad, 2010, 19-36.

Sambricio, Carlos: Territorio y ciudad en la España de la Ilustración, Madrid, Ministerio de Obras Públicas y Transportes, 1991.

Sambricio, Carlos: «Sinapia. Utopía, territorio y ciudad a finales del siglo XVIII», Scripta Nova. Revista electrónica de Geografía y Ciencias Sociales, XVIII475, Barcelona, 2014. http://www.ub.edu/geocrit/sn/sn-475.htm

Sanz de la Higuera, Francisco J.: «Embajadas rodantes de Antiguo Régimen: los forlones, berlinas y carrozas de los pecheros. Una estancia doméstica que se mueve. Entre las calles y las casas de Burgos a mediados del siglo XVIII (I) y (II)», Boletín de la Institución Fernán González, 225-226, Burgos, 20022003, 269-291 y 35-59.

Sanz Sanjosé, María Gloria: «Espacios urbanos de ocio: la Alameda del Parral de Segovia», Didáctica Geográfica, 7, Madrid, 2005, 551-573.

Sica, Paolo: La imagen de la ciudad. De Esparta a Las Vegas, Barcelona, Editorial Gustavo Gili, 1977.

Sica, Paolo: Historia del urbanismo. El siglo XVIII, Madrid, Instituto de Estudios de Administración Local, 1982.

Solís de los Santos, José: «El trasfondo humanista de la Alameda de Sevilla», Calamvs Renascens, 13, Alcañiz, 2012, 75-138.

Twiss, Richard: Viaje por España en 1773, Madrid, Cátedra, 1999 [1775].

Val Valdivieso, María Isabel del: Agua y poder en la Castilla bajomedieval, Valladolid, Universidad de Valladolid, 2003. 